\section{Energy-saving Seedling Production System for Super-forcing Cultivation of June-bearing Commercial Strawberry}

\author{
Ryoichi Nakajima, Shungo Otagaki, Katsuhiro Shiratake, \\ and Shogo Matsumoto ${ }^{1}$ \\ Graduate School of Bioagricultural Sciences, Nagoya University, Chikusa, \\ Nagoya 464-8601, Japan
}

Additional index words. flowering, Fragaria $\times$ ananassa, photoperiod, temperature

Abstract. Previously, we showed that a reduction of FaTFL2 (homolog of Arabidopsis thaliana TFL1) expression is a key signal for flowering in domesticated octaploid strawberries (Fragaria $\times$ ananassa). Since FaTFL2 expression seemed to be regulated by temperature rather than by photoperiod, we investigated whether down regulation of FaTFL 2 and floral meristem generation occurred at different temperature conditions. In addition to the conditions for a normal super-forcing cultivation system of an 8-hour photoperiod and day/night temperatures of 31.2 or $30 / 15{ }^{\circ} \mathrm{C}$, flowering also was generated under the same photoperiod and day/night temperatures of day/night-half/ night-half temperatures of $30 / 15 / 25{ }^{\circ} \mathrm{C}$ conditions. We demonstrate that the new superforcing cultivation system is energy saving based on the reduction of FaTFL 2 expression.

June-bearing commercial strawberries (Fragaria $\times$ ananassa) are preferable to everbearing ones for Japanese consumers due to their high quality. The June-bearing strawberry is typically a short day and low temperature (SDLT) type plant, and its harvesting time under natural conditions is from March to May or from November to May under a heating system during the winter. Autumn is the off-season, however, not only for consumers, but also confectionery makers who desire the June-bearing type in autumn. SDLT types can initiate flowering under $15{ }^{\circ} \mathrm{C}$ ( or $17{ }^{\circ} \mathrm{C}$ ) regardless of the photoperiod conditions, but inhibition of flowering occurs at high temperature ( 25 to $26{ }^{\circ} \mathrm{C}$ ) conditions even under a short photoperiod (Bradford et al., 2010; Taylor, 2002; Verheul et al., 2006).

A super-forcing cultivation system has been developed in Japan for producing SDLT type strawberries from September to November (Yamasaki et al., 2003). The SDLT plants are grown in the field during daytime (average $31.2^{\circ} \mathrm{C}$ ), but they are placed into a curtained tunnel tent with air cooling $\left(15^{\circ} \mathrm{C}\right)$ from $1700 \mathrm{HR}$ to $900 \mathrm{HR}$ for $30-35 \mathrm{~d}$ to induce flower buds (Nakajima et al., 2014). As the system consumes a lot of energy, energy saving technology is strongly desired in

Received for publication 26 Dec. 2014. Accepted for publication 2 Mar. 2015.

We are indebted to Dr. Tetsuya Oyabu for his useful suggestions. We thank Mr. Shoji Niwa and Mr. Kenji Kato for supplying runner plants of cultivar Fragaria xananassa Tochiotome with their valuable technical assistance. This research was supported by the Adaptable and Seamless Technology Transfer Program from the Japan Science and Technology Agency.

${ }^{1}$ To whom reprint requests should be addressed; e-mail shogo@agr.nagoya-u.ac.jp.
Japan, especially after the Great East Japan Earthquake on 11 Mar. 2011.

Previously, we clarified that a reduction of FaTFL2 expression is a key signal for flowering in SDLT type commercial strawberries, by temperature rather than photoperiod (Nakajima et al., 2014). In this study, we showed the reduction of FaTFL2 expression could be used as an indicator for flower initiation, and also demonstrated a new superforcing cultivation system under a higher temperature condition than the previous condition, which leads to energy saving.

\section{Materials and Methods}

Plants and cultivation. Runner plants of Fragaria $\times$ ananassa $\mathrm{cv}$. Tochiotome strawberry having three expanded leaves were cut off and planted in pots. We removed the and its expression seems to be regulated leaves from the plants with the exception of three to five sets of the youngest fully developed leaves. For analyzing the temperature effect on strawberry flowering, we placed the 'Tochiotome' plants in a growth chamber under expected flower noninductive short day and high temperature conditions (SDHT 30/25; an 8-h light at $30^{\circ} \mathrm{C}$ and a 16-h dark at $25{ }^{\circ} \mathrm{C}$, used as a negative control), short day and middle temperature conditions (SDMT 30/20; an 8-h light at $30{ }^{\circ} \mathrm{C}$ and a 16-h dark at $20^{\circ} \mathrm{C}$ ), flower inductive SDLT conditions (SDLT 30/15; an 8-h light at $30^{\circ} \mathrm{C}$ and a 16 -h dark at $15^{\circ} \mathrm{C}$, used as a positive control), and short day and half low temperature conditions (SDHLT 30/15/25; an 8-h light at $30^{\circ} \mathrm{C}$, an 8 -h dark at $15^{\circ} \mathrm{C}$, and an 8 -h dark at $25^{\circ} \mathrm{C}$ ) to find the correlation between FaTFL2 expressions and flower bud formation (Fig. 1). We sampled the crowns of 'Tochiotome' plants on $0,20,25,30$, and 35th day after the SDHT, SDMT, SDLT, and SDHLT treatments. Tissues were stored at $-80^{\circ} \mathrm{C}$.

Flower buds differentiation. We investigated the developmental stages of the flower buds on samples of SDHT 31.2/15 (an 8-h light at $31.2^{\circ} \mathrm{C}$ average/a 16 -h dark at $15^{\circ} \mathrm{C}$ ) at 2013, and those of SDHT 30/25, SDMT 30/ 20, SDLT 30/15, and SDHLT 30/15/25 at 2014 by microscope. The developmental stages of the flower buds were defined as: stage 0 - an undifferentiated stage, stage A1A3 - an initial to late differentiation stage, stage B1-B3 - an initial to late flower cluster formation stage, stage $\mathrm{C}$ - an initial sepal formation stage, and stage $\mathrm{D}$ - an involucre formation stage.

$R N A$ extraction. Total RNA was isolated using the hot borate method described in Wan and Wilkins (1994) with some modifications. A detailed protocol is in our previous paper (Nakajima et al., 2014).

Quantitative real-time polymerase chain reaction ( $(P C R$ ) analyses of FaTFL1-1 and FaTFL2 genes. Quantification of transcripts for FaTFL1-1 and FaTFL2 was conducted using the SYBR Premix Ex Taq II (Tli RNaseH Plus; TaKaRa Bio Inc., Shiga, Japan) and the thermal cycler Dice Real Time

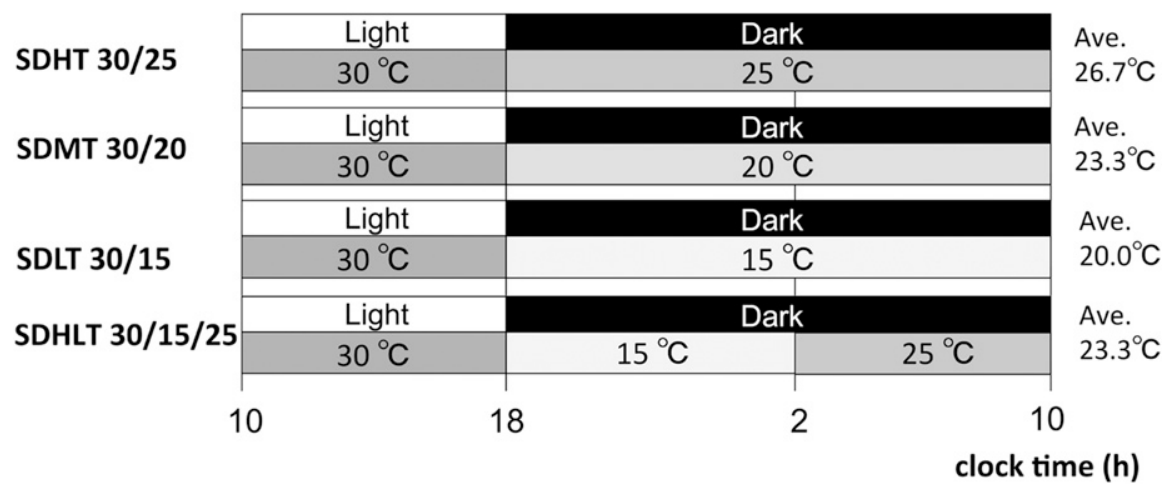

Fig. 1. Different temperature conditions of Fragaria $\times$ ananassa Tochiotome for super-forcing cultivation. Short day and high temperature (SDHT) 30/25; SDHT (an 8-h light at $30{ }^{\circ} \mathrm{C}$ and 16 -h dark at $25^{\circ} \mathrm{C}$, negative control), short day and middle temperature (SDMT) 30/20; short day and low temperature (SDLT) (an 8-h light at $30^{\circ} \mathrm{C}$ and 16 -h dark at $20^{\circ} \mathrm{C}$ ), SDLT $30 / 15$; an 8 -h light at $30{ }^{\circ} \mathrm{C}$ and 16 -h dark at $15{ }^{\circ} \mathrm{C}$ ), short day and half low temperature (SDHLT) 30/15/25 (an 8-h light at $30{ }^{\circ} \mathrm{C}, 8$-h dark at $15^{\circ} \mathrm{C}$ and 8 -h dark at $25^{\circ} \mathrm{C}$ ). All 'Tochiotome' plants were grown in a growth chamber. 
System TP800 (TaKaRa Bio Inc.). MSI1 was used as housekeeping gene (Mouhu et al., 2009). Complementary DNA was synthesized using a PrimeScript reverse transcriptase reagent kit with genomic DNA eraser (TaKaRa Bio Inc.). The primer sets are listed in Table 1. qPCR conditions were preheating for $30 \mathrm{~s}$ at $95{ }^{\circ} \mathrm{C}$, followed by 45 cycles of $5 \mathrm{~s}$ at $95^{\circ} \mathrm{C}, 10 \mathrm{~s}$ at $60^{\circ} \mathrm{C}$, and $25 \mathrm{~s}$ (for FaTFL1-1) or $20 \mathrm{~s}$ (for FaTFL2) at $72{ }^{\circ} \mathrm{C}$. The data were analyzed with a Thermal cycler Dice Real-Time System Software Ver. 3.00D (TaKaRa Bio Inc.). The relative expression of each sample was normalized to the MSII gene. The expression of FaTFL1-1 or FaTFL2 in three biological replicates at $0 \mathrm{~d}$ was used as a reference and was set as 1 -fold. qPCR expression analysis was performed using three independent RNA preparations (three biological replicates) per stage, and data are shown as mean \pm SE.
Table 1. Primer sets for quantitative real-time polymerase chain reaction analyses.

\begin{tabular}{lll}
\hline Primer & \multicolumn{1}{c}{ Oligonucleotides $\left(5^{\prime} \rightarrow 3^{\prime}\right)$} & Reference \\
\hline FaTFL1F & CACCTCGACTGGATTGTGAC & This study \\
FaTFL1R & TTTGGGATCTGGCCTGCCTC & This study \\
FaTFL2F & TGACAGTGACTTACAACTCC & This study \\
FaTFL2R & CCTCCCTTCCAAATGTGTTG & This study \\
MSI1F & TCTCCACACCTTTGATTGCCA & Mouhu et al. (2009) \\
MSI1R & ACACCATCAGTCTCCTGCCAAG & Mouhu et al. (2009) \\
\hline
\end{tabular}

\section{Results and Discussion}

In the super-forcing cultivation system for June-bearing commercial strawberry, the plants are grown under SDLT conditions for 30 to $35 \mathrm{~d}$ (SDLT 31.2/15; an 8-h photoperiod from $0900 \mathrm{HR}$ to $1700 \mathrm{HR}$, average $31.2^{\circ} \mathrm{C}$ at outside /a 16-h dark from $1700 \mathrm{HR}$ to $900 \mathrm{HR}$,
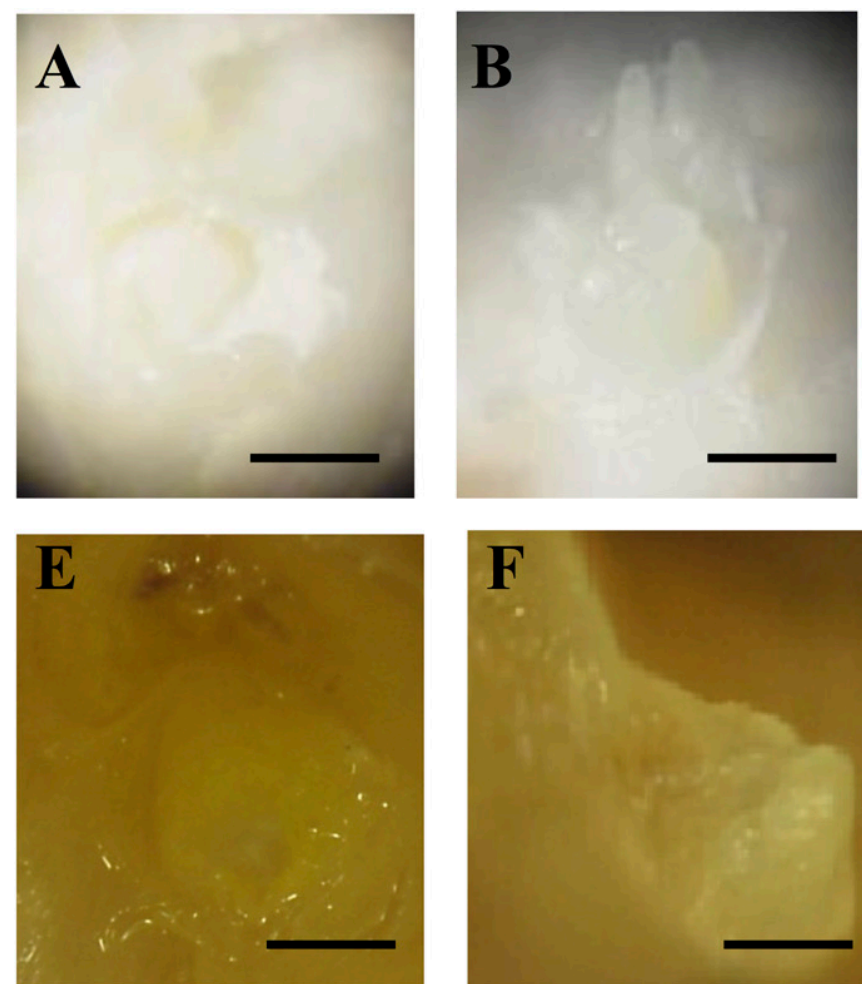
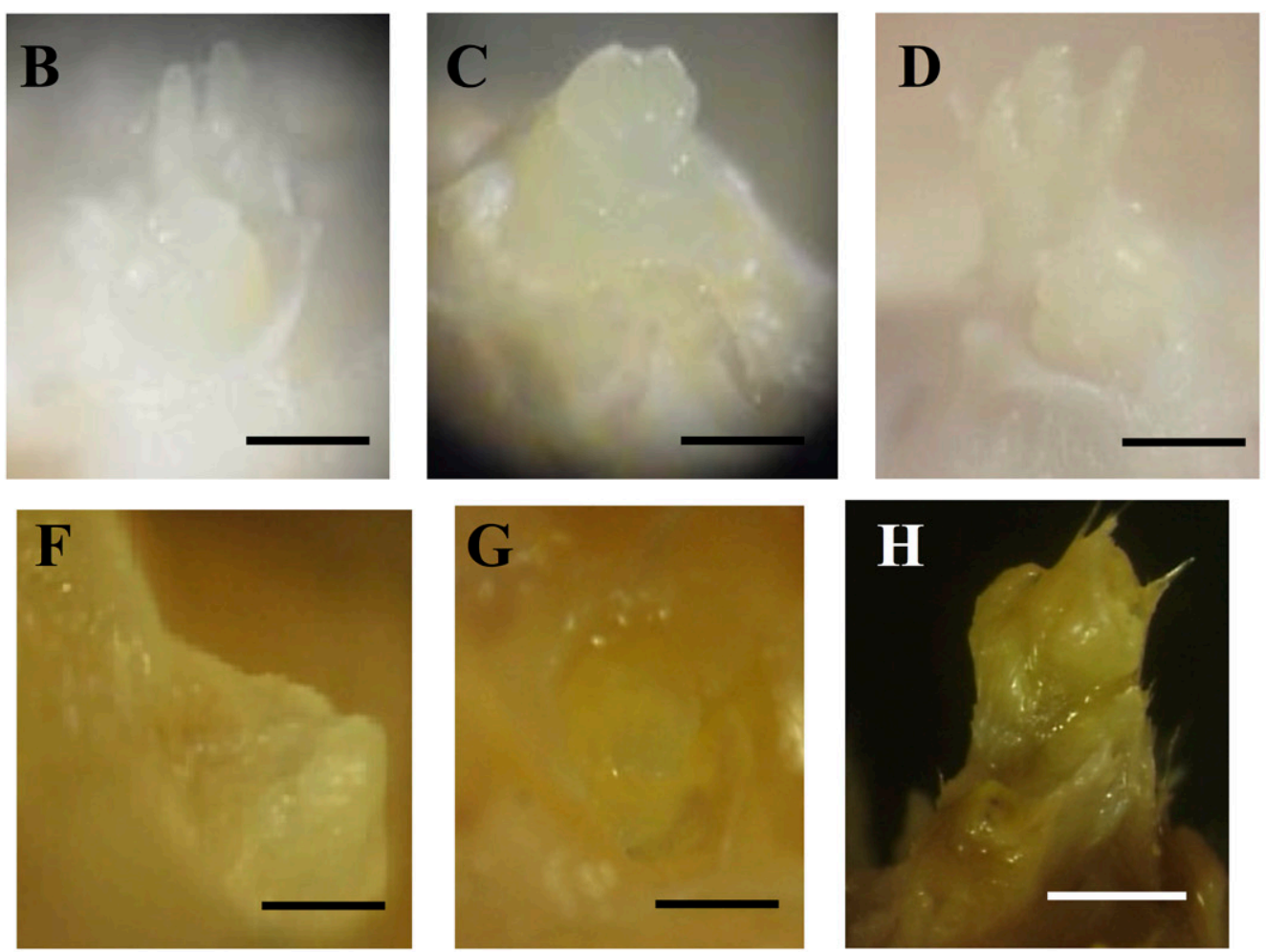

Fig. 2. Flower bud differentiation process of Fragaria $\times$ ananassa Tochiotome. (A) $25 \mathrm{~d}$ after short day and low temperature (SDLT) $31.2 / 15$ (SDLT condition, 8 -h light at $31.2^{\circ} \mathrm{C}$ average/ 16 -h dark at $15^{\circ} \mathrm{C}$ ) treatment. A growing point is flat and undifferentiated (stage 0$) .(\mathbf{B}) 30 \mathrm{~d}$ after SDLT $31.2 / 15$ treatment. A growing point is roundish and upheaves (stage A3). (C) $35 \mathrm{~d}$ after SDLT 31.2/15 treatment. A flower cluster is formed, and formation of the piece of sepal starts in a terminal flower bud (stage C). (D) $35 \mathrm{~d}$ after short day and high temperature (SDHT) $25 / 25$ (SDHT condition, 8 -h light at $25^{\circ} \mathrm{C} / 16$-h dark at $25^{\circ} \mathrm{C}$ ) treatment. A flower cluster is developed (stage B2). (E) $30 \mathrm{~d}$ after SDHT 30/25 treatment, stage 0. (F) $30 \mathrm{~d}$ after short day and middle temperature (SDMT) 30/20 treatment, stage 0. (G) $30 \mathrm{~d}$ after SDLT 30/15 treatment, a flower cluster is developed (stage B2). (H) $30 \mathrm{~d}$ after short day and half low temperature 30/15/25 treatment. Formation of involucre becomes in a terminal flower bud (stage D). Stage 0; undifferentiated stage, stage A1-A3; initial to late differentiation stage, stage B1-B3; initial to late flower cluster formation stage, stage C; initial sepal formation stage, stage D; involucre formation stage. Scale bars $=1000 \mu \mathrm{m}(\mathbf{A}$ to D) or $500 \mu \mathrm{m}(\mathbf{E}$ to $\mathbf{H})$.

Table 2. FaTFL1-1 and FaTFL2 expression determined by quantitative real-time polymerase chain reaction in crowns of Fragaria $\times$ ananassa Tochiotome grown under different conditions for 0 to $35 \mathrm{~d}$. The transcription relative to housekeeping gene MSI1. Means $\pm \mathrm{SE}, n=3$.

\begin{tabular}{|c|c|c|c|c|c|c|}
\hline Gene & Temperature & $0 \mathrm{~d}^{\mathrm{z}}$ & $20 \mathrm{~d}$ & $25 \mathrm{~d}$ & $30 \mathrm{~d}$ & $35 \mathrm{~d}$ \\
\hline \multirow[t]{4}{*}{$\overline{F a T F L 1-1}$} & SDHT 30/25 & 1.00 & $0.45 \pm 0.24$ & $0.21 \pm 0.07$ & $0.27 \pm 0.14$ & $0.21 \pm 0.03$ \\
\hline & SDMT $30 / 20$ & 1.00 & $0.30 \pm 0.12$ & $0.05 \pm 0.02$ & $0.02 \pm 0.00$ & $0.12 \pm 0.02$ \\
\hline & SDLT 30/15 & 1.00 & $0.25 \pm 0.10$ & $0.17 \pm 0.05$ & $0.30 \pm 0.06$ & $0.23 \pm 0.14$ \\
\hline & SDHLT $30 / 15 / 25$ & 1.00 & $0.28 \pm 0.08$ & $0.34 \pm 0.14$ & $0.35 \pm 0.14$ & $0.15 \pm 0.05$ \\
\hline \multirow[t]{4}{*}{ FaTFL2 } & SDHT 30/25 & 1.00 & $0.43 \pm 0.15$ & $0.42 \pm 0.23$ & $0.25 \pm 0.08$ & $0.33 \pm 0.13$ \\
\hline & SDMT $30 / 20$ & 1.00 & $0.41 \pm 0.09$ & $0.24 \pm 0.11$ & $0.20 \pm 0.12$ & $0.28 \pm 0.10$ \\
\hline & SDLT 30/15 & 1.00 & $0.06 \pm 0.01$ & $0.07 \pm 0.03$ & $0.17 \pm 0.09$ & $0.10 \pm 0.02$ \\
\hline & SDHLT $30 / 15 / 25$ & 1.00 & $0.07 \pm 0.02$ & $0.04 \pm 0.01$ & $0.04 \pm 0.02$ & $0.08 \pm 0.05$ \\
\hline
\end{tabular}

${ }^{\mathrm{z}}$ Average expression values of each gene in three biological replicates were calculated regardless of the treatments and were set as 1 -fold. SDHT $=$ short day and high temperature; SDMT = short day and middle temperature; SDLT = short day and low temperature; SDHLT $=$ short day and half low temperature. 
$15^{\circ} \mathrm{C}$ ) in summer to promote floral bud initiation. Previously, we found that floral bud differentiation occurred under short day and high temperature conditions (SDHT 25/ 25; an 8-h light, $25^{\circ} \mathrm{C} /$ a 16 -h dark $25^{\circ} \mathrm{C}$ ) (Fig. 2D; Nakajima et al., 2014). As the down regulation of FaTFL2 gene responsible for floral bud initiation occurred dependently of temperature rather than photoperiod, we investigated the floral bud development under short day and different temperature conditions.

As shown in Table 2, the expression level of FaTFL2 was markedly reduced after 20 and $25 \mathrm{~d}$ at SDLT 30/15 (an 8-h light, $30^{\circ} \mathrm{C} /$ a 16 -h dark, $15^{\circ} \mathrm{C}$; used as a positive control) and SDHLT 30/15/25 (an 8-h light, $30^{\circ} \mathrm{C} /$ an 8-h dark, $15^{\circ} \mathrm{C} /$ an 8 -h dark, $25^{\circ} \mathrm{C}$ ) compared with day 0 . We observed flower buds at stages 0 (undifferentiated), A3 and C (differentiated) on samples after 25,30 , and $35 \mathrm{~d}$ of SDLT 31.2/15, respectively, in 2013 (Fig. $2 \mathrm{~A}-\mathrm{C}$ ), and observed those of stages $\mathrm{B} 2$ and $\mathrm{D}$ (differentiated) on samples after $30 \mathrm{~d}$ of SDLT 30/15 and SDHLT 30/15/25, respectively, in 2014 (Fig. 2G and H). Contrarily, no flower buds were observed on samples after $30 \mathrm{~d}$ at SDHT 30/25 (an 8-h light, $30^{\circ} \mathrm{C} / \mathrm{a}$ 16-h dark, $25^{\circ} \mathrm{C}$; used as a negative control) and SDMT 30/20 (an 8-h light, $30^{\circ} \mathrm{C} / \mathrm{a}$ 16-h dark, $20^{\circ} \mathrm{C}$ ) in 2014 (Fig. 2E and F). The samples after $35 \mathrm{~d}$ of SDLT $30 / 25$ also showed flower buds of undifferentiated stage 0 , however, some samples after $35 \mathrm{~d}$ of SDMT $30 / 20$ showed the $0 \approx A 1$ stage (results not shown). Although it was difficult to judge exactly either the undifferentiated stage 0 or the incipient beginning of flower bud formation at stage $\mathrm{A} 1$, the floral bud differentiation might occur under the SDMT $30 / 20$ condition. In case of SDHT 30/25 (an 8-h light, $30^{\circ} \mathrm{C} / \mathrm{a} 16$-h dark, $25^{\circ} \mathrm{C}$ ), $57 \%$ and $58 \%$ reduction of the FaTFL 2 expression was observed at 20 and $25 \mathrm{~d}$ compared with day 0 , which was lower compared with $93 \%$ and $94 \%$ reduction of SDLT 30/15 and SDHLT $30 / 15 / 25$ (Table 2). The $57 \%$ and $58 \%$ reduction of FaTFL2 expression seemed to be inadequate for flower bud initiation. The same reduction level $(59 \%)$ of the FaTFL2 expression after $20 \mathrm{~d}$ compared with day
0 was also observed in SDMT 30/20, however, greater reduction of $76 \%$ was observed after $25 \mathrm{~d}$ compared with day 0 . Stages $0 \approx$ A1 at $35 \mathrm{~d}$ in SDMT 30/20 might be caused by this reduction and/or the FaTFL1-1 reduction (Table 2).

In our previous results, no reduction of FaTFL $1-1$ at 20 to $35 \mathrm{~d}$ after the treatments was observed under the flower inductive SDLT 31.2/15 condition (Nakajima et al., 2014), suggesting that the gene was expressing mainly in the area of the crown of no correlation with flower bud differentiation. However, we observed the reduction of FaTFL1-1 expression at 20 and 25 d of both the noninductive and inductive conditions, that is, $55 \%$ to $83 \%$ reduction, and the most severe reduction was observed at 25 to $35 \mathrm{~d}$ of SDMT 30/20 (Table 2). The difference of the expression level of FaTFL1-1 might be from the difference of the maximum temperature condition between SDLT 31.2/15 and short day (SD) temperatures of $30 / 25,30 / 20,30 /$ 15 , and $30 / 15 / 25$. In the SDLT $31.2 / 15$ condition, average temperature outside of $0900 \mathrm{HR}$ to $1700 \mathrm{HR}$ was $31.2{ }^{\circ} \mathrm{C}$, which is close to the $30^{\circ} \mathrm{C}$ of SD-temperatures of $30 /$ $25,30 / 20,30 / 15$, and $30 / 15 / 25$, but rising to $36.1{ }^{\circ} \mathrm{C}$ at $1400 \mathrm{HR}$ at the end of July. We observed the reduction of FaTFL1-1 expression at temperate conditions not rising more than $30{ }^{\circ} \mathrm{C}$, and the severe reduction of FaTFL1-1 in this condition $(95 \%$ at $25 \mathrm{~d})$ might relate to the stage $0 \approx \mathrm{A} 1$ at $30 \mathrm{~d}$ of SDMT 30/20 (Table 1).

Interestingly, although the average temperatures of SDMT 30/20 and SDHLT 30/15/ 25 are the same $\left(23.3^{\circ} \mathrm{C}\right)$, the marked reduction of the FaTFL2 gene with clear flower bud differentiation occurred at SDHLT 30/ $15 / 25$, not SDMT $30 / 20$, suggesting that temperature drops below $15{ }^{\circ} \mathrm{C}$ at dark after $30^{\circ} \mathrm{C}$ at light might be important for FaTFL2 reduction and floral bud differentiation. Since flower buds were induced under the SDHLT $30 / 15 / 25$ conditions in addition to the SDLT $30 / 15$ conditions used as a positive control, half reduction of the energy cost would be possible if the temperature of $25^{\circ} \mathrm{C}$ at the 8 -h dark period could be maintained without cooling.
The plants are grown in the field from $0900 \mathrm{HR}$ to $1700 \mathrm{HR}$ with the temperature rising more than $30{ }^{\circ} \mathrm{C}$ (average $31.2{ }^{\circ} \mathrm{C}$ ), then sheltered in a curtained tunnel tent with air cooling $\left(15^{\circ} \mathrm{C}\right)$ from $1700 \mathrm{HR}$ to $0900 \mathrm{HR}$ in the case of normal super-forcing cultivation. Since the average temperature outside at $0100 \mathrm{HR}$ to $0900 \mathrm{HR}$ is $26.7^{\circ} \mathrm{C}$ which is close to $25{ }^{\circ} \mathrm{C}$, it might be possible to turn off the switch for cooling in a curtained tunnel tent during $0100 \mathrm{HR}$ to $0900 \mathrm{HR}$. This means half reduction of the energy costs of super-forcing strawberry cultivation. Moreover, more than 93\% FaTFL 2 reduction at 20 and/or $25 \mathrm{~d}$ after treatment of SDHLT could provide an alternative method to a conventional microscopic observation of a growing point for determining whether floral differentiation occurred, since a number of samples can be analyzed at one time once some molecular biological tools are set up.

\section{Literature Cited}

Bradford, E., J.F. Hancock, and R.M. Warner 2010. Interactions of temperature and photoperiod determine expression of repeat flowering in strawberry. J. Amer. Soc. Hort. Sci. 135:102-107.

Mouhu, K., T. Hytönen, K. Folta, M. Rantanen, L. Paulin, P. Auvinen, and P. Elomaa. 2009. Identification of flowering genes in strawberry, a perennial SD plant. BMC Plant Biol. 9:122.

Nakajima, R., S. Otagaki, K. Yamada, K. Shiratake, and S. Matsumoto. 2014. Molecular cloning and expression analyses of FaFT, FaTFL, and FaAPl genes in cultivated strawberry: Their correlation to flower bud formation. Biol. Plant. 58:641-648.

Taylor, D.R. 2002. The physiology of flowering in strawberry. Acta Hort. 567:245-251.

Verheul, M.J., A. Sønsteby, and S.O. Grimstad. 2006. Interactions of photoperiod, temperature, duration of short-day treatment and plant age on flowering of Fragaria $\times$ ananassa Duch. cv. Korona. Sci. Hort. 107:164-170.

Wan, C.-Y. and T.A. Wilkins. 1994. A modified hot borate method significantly enhances the yield of high-quality RNA from cotton (Gossypium hirsutum L.). Anal. Biochem. 223:7-12.

Yamasaki, A., T. Yano, and H. Sasaki. 2003. Outof-season production of strawberry: Effects of a short-day treatment in summer. Acta Hort. 626:277-282 